\title{
Mahnmal statt Jubiläum*: \\ Nährboden und Grundlage kirchlicher Zensur vor und nach 1479
}

\author{
von Joan Hemels
}

Vor genau fünfhundert Jahren verlieh ein Breve von Papst Sixtus IV. der Kölner Universität als geistlicher Zensurbehörde ein zeitlich wie örtlich unbeschränktes Recht zur Zensur. Durch die Diskussion vor und nach der Mediendeklaration der UNESCO von 1978 ist im Bereich der internationalen Kommunikation die Frage der Zensur für die Länder der sogenannten „Dritten Welt” besonders wichtig. Sie befürchten eine geistige Überfremdung und möchten aufgrund eigener politischer Interessen die Kommunikationsflut aus den westlichen Staaten steuern. In der Sowjetunion und den meisten Ländern des sozialistischen Lagers, aber auch in manchen sich „demokratisch” nennenden westlichen Ländern ist die Meinungsfreiheit - wenn auch verdeckt - oft mehr Ideal als Wirklichkeit. Beispiele der Zensurpraxis gibt es manchmal bis in unsere Tage hinein bei Kirchen, Universitäten, den Massenmedien selbst und anderen Institutionen. Kommunikationskontrolle, das Regeln und Lenken der Kommunikation hat eine ältere Geschichte als die Grundforderung der Kommunikationsfreiheit. Durch das Zusammenwirken von Kirche und Staat wurde die Präventivzensur der Reflex der Angstgefühle bei den Umwälzungen des christlichen Europas am Ende des 15. Jahrhunderts. Die kirchliche Zensurpraxis bekam nicht nur durch den bekannten und seit 1966 nicht mehr existierenden Index einen schlechten Ruf. Die katholische Kirche unternahm schon früher große Anstrengungen, Einfluß auf das Bücher- und Pressewesen zu gewinnen, wie aus den nachfolgenden Forschungen deutlich wird.

„Selten sind die glücklichen Zeiten, wo man meinen kann, was man will, und sagen, was man meint”. (,Rara temporum felicitas, ubi sentire, quae / velis, et quae sentias, dicere licet"). Mit diesen, Tacitus, Historien I, 1 entnommenen Worten, beendete Franz Schneider einen Beitrag über die Freiheit der Meinungsäußerung in der griechischen Demokratie und römischen Republik ${ }^{1}$. Tacitus dokumentierte die Entwicklung der Gedankenfreiheit in seiner Zeit; seine Aussage aber kann mit Recht Dauergültigkeit beanspruchen. Schneider hatte sich das Ziel gesetzt, in Form eines Überblicks den wichtigsten Entwicklungslinien von Kommunikationsfreiheit im Altertum nachzugehen und Weitererforschungen anzuregen.

\section{Vorgeschichte der Pressezensur}

Es wäre, so Schneider, unrichtig, aus der fehlenden verfassungsmäßigen Formulierung eines Rechtes auf Meinungsfreiheit in der griechischen Demokratie auf das Fehlen eines faktischen Vorhandenseins dieser Freiheiten zu schließen. Es gebe zwei Argumente: einerseits steht es fest, daß die damalige Demokratie eine wirkliche Herrschaft des Volkes war, die ohne Freiheit der Bürger nicht denkbar gewesen sei, andererseits liegt die Folgerung nahe, die Freiheit des einzelnen sei eine solche Selbstverständlichkeit gewesen, daß niemand auf den Gedanken kam, sie verbriefen zu wollen. Die Notwendigkeit einer Kodifikation war solange umso weniger gegeben, als

Dr. Joan Hemels ist wissenschaftlicher Hauptmitarbeiter am Psychologischen Institut der Katholischen Universität Nimwegen. 
die Verurteilung gewisser Übergriffe und Mißbräuche in der Meinungsäußerung durch eine nahezu einstimmige „öffentliche Meinung” ebenso selbstverständlich war wie das Recht selbst.

Als zentrale Belegstelle für die Freiheitsprinzipien der klassischen Zeit nennt Schneider die berühmte Totenrede des Perikles aus dem Jahre 430 v. Chr., aus der insbesondere auch die Bedeutsamkeit ungeschriebener Gesetze hervorgeht.

Die Redefreiheit (eleutheros legein) wurde als Voraussetzung der wahren Demokratie und als Grundlage des Staatswohls gesehen. In Athen entwickelte sich, beginnend mit der Zeit des Perikles (448-431 v. Chr.), weit über ein Jahrhundert hin auf der Grundlage der Redefreiheit die Redekunst. Der Wirkungsbereich des bedeutenden Redners verlagerte sich immer mehr aus dem Bezirk gerichtlicher Anwaltstätigkeit auf das Gebiet der Staatsführung, wo die Rede insbesondere durch Demosthenes größte Bedeutung erlangte. In der hellenistischen Zeit (336-30 v. Chr.) schien der Mißbrauch der Redefreiheit (Schmähsucht und Beleidigung) immermehr zugenommen zu haben.

Übrigens gab es in der griechischen Antike stets zwei kennzeichnende Einschränkungen der existierenden Libertät: das volle Maß der Freiheit genoß nur der Vollbürger, denn nur er war an der Mitgestaltung der Polis aktiv beteiligt. Ähnlich war die Stellung der Frau durch völlige Politikferne gekennzeichnet, und ein Recht der freien Meinungsäußerung war hier weitgehend gegenstandslos. Eine gewisse Einschränkung erfuhr die freizügige Gestaltung des Geisteslebens in der Religionsfreiheit, insbesondere in der geringen Toleranz gegenüber minoritären Kulten.

Das Römertum hatte in seiner Frühzeit die Unterdrückung glaubensfeindlicher Schriften mit dem Griechentum gemein. Diese Einstellung änderte sich aber seit 149 v.Chr., und man war bereits lange vor der Zeitenwende stolz darauf, die Ideen der modernen griechischen Philosophenschulen für das römische Geistesleben „erobert” zu haben. Dagegen mußte bei politischen Äußerungen über die Verhältnisse im Staate immer größere Vorsicht Platz greifen. Schneider stellte fest, daß für den Römer neben den Begriff libertas die auctoritas tritt, und daß beide Begriffe sich gegenseitig begrenzen. Für die Redefreiheit bedeutete dies, daß nur derjenige das Wort erhielt, der auctoritas hatte, d.h. daß nur der frei reden durfte, von dem man glaubte, daß er auch wirklich etwas zu sagen habe. Hier zeigt sich ein erhebliches Minus im Verhältnis zur griechischen Demokratie, aber es handelt sich dabei nur um die Freiheit unmittelbarer Mitwirkung bei politischen Entscheidungen, die lediglich einen Ausschnitt aus der Meinungsfreiheit darstellt.

Der allmähliche Verfall der römischen Redefreiheit bahnte sich bereits zu einer Zeit an, da die Redekunst noch in voller Blüte stand. Das letzte Jahrhundert der res publica (133-30 v. Chr.) bewirkte die Krise des libertas-Gedankens. Äußere Gewalt brachte den Austausch der Meinungen nicht zum Erliegen: das echte Zeitgespräch versiegte zwar nicht, aber es zog sich in das Souterrain der Öffentlichkeit zurück, wie Schneider es umschreibt. Bereits das Zwölftafelgesetz vom Jahre 450 v. Chr. enthielt eine Bestimmung, denjenigen zu bestrafen, der „ein Spottgedicht anstimmte oder ein Schmähgedicht verfaßte, das einem anderen zur Unehre oder Schande gereichte" 2 . Es scheint daher die Überwachung des Schrifttums im römischen Reich vor allem auf sogenannte Schmäh- und Spottschriften („libelli famosi”), d.h. Schriften mit beleidigendem Inhalt, beschränkt gewesen zu sein ${ }^{3}$, denn „eine Zensur im Sinne 
unseres heutigen Staats- oder Kirchenrechtes kannten die alten Kulturstaaten nicht, jedenfalls nicht die Präventivzensur. Die Staatsgewalt kannte keine Institutionen, denen mit ausdrücklicher staatlicher Vollmacht die Prüfung des Schrifttums oblag. Auch gab es weder Gesetze noch Verordnungen, die dem Staat das Recht gaben, eine Prüfung der Schriftwerke vorzunehmen", wie Erich Traumann feststellt ${ }^{4}$.

Empfindlich reagierten jedoch auch die Römer - ähnlich wie die Griechen - bei jenen Fällen, in denen minoritäre Kulte oder Religionen wesentlich von den als verbindlich anerkannten Glaubensgrundsätzen abwichen. Das unter Kaiser Konstantin 324 n.Chr. zur Staatsreligion erhobene Christentum übernahm nunmehr seinerseits „die Waffe der Schriftenverfolgung", womit die Freiheit der antiken Geisteswelt zu Ende war,

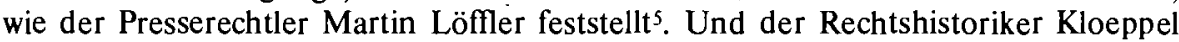
ergänzt: „So überlieferte das Altertum dem Mittelalter nahezu den vollen Bestand der Strafbestimmungen für Gedankenäußerung." ${ }^{6}$ Nach 1200, so führt Löffler weiter aus, wurden beispielsweise die Waldenser von seitens der Kirche eingerichteten Inquisitionsbehörden verfolgt und ihre Schriften vernichtet. Nach einem Gesetz des Staufenkaisers Friedrich II. von 1222 galt die Verbrennung als sozusagen „normale Strafe” für den Abfall von den kirchlichen Lehren; „ketzenische Schriften” hatten ebenfalls verbrannt zu werden.

Die katholische Kirche gilt oft als die Erfinderin heimtückischer Abwehrmaßnahmen, die wir heute unter den Begriff der Zensur zusammenzufassen gewohnt sind. Ein Blick in das Staats- und Rechtsleben der Kulturstaaten in der Antike zeigt, daß in der Praxis der kirchlichen Zensur nicht eine neue Erfindung zu sehen ist. Nur spärliche Überreste zeugen davon, daß den Trägern der staatlichen Gewalt zu allen Zeiten und bei allen Völkern nichts unbequemer war als Reden und Schriften, die entweder den Staat zu Recht oder zu Unrecht in seinen Repräsentanten angriff oder den Bestand der Ordnung gefährdeten und so geeignet erscheinen mußten, Ansehen und Ordnung und sogar Bestand des Staatswesens zu gefährden. Ein katastrophales Beispiel staatlicher Zensur im Reich der Chinesen war die Bücherverbrennung vom Jahre 213 v. Chr., unter Kaiser Tshin-schi-Quang-ti, Gründer des Chinesischen Einheitsstaates und Bauherr der bekannten großen Mauer.

Als sicherstes und einfachstes Mittel zur Kontrolle des Inhaltes von Buchdrucken gilt die Vorzensur. Für sie ist Plato ein glänzender Befürworter. In dem Dialog über die Dichter im Buch 7 der Gesetze äußert sich der 'Athener' über die Zensur an einer Stelle, die wegen ihrer leuchtenden Klarheit in dieser Frage hier wörtlich angeführt werden soll: „Der Dichter darf in seinen Dichtungen sich keinerlei Abweichung erlauben von dem, was im Staate als gesetzlich, als recht, als schön und gut in Geltung steht und er darf die Erzeugnisse seiner Dichtkunst keinem Privatmanne eher mitteilen, als bis sie den eigens dafür bestellten Richtern und Gesetzeswächtern vorgelegt worden sind und deren Billigung gefunden haben. Als solche sind aber von uns wohl deutlich genug schon diejenigen bestellt, die wir zu Gesetzgebern für die Musik erwählten und neben ihnen die Vorsteher des Erziehungswesens. Wie also? Soll - um immer noch fortzufahren in meinen Fragen - dies als drittes Gesetz und Norm für uns festgestellt sein?” Kleinias antwortet darauf: „Kein Zweifel, es soll Gesetzeskraft haben."

Dennoch ist diese präventive Zensur in der Gesetzgebung vor Erfindung des Buchdruckes etwas Unbekanntes. Allerdings haben die Staats- und Kirchenbehörden mit großer Strenge darüber gewacht, wie die zahlreichen Titel „de haereticis et schismaticis” 
der kirchlichen und staatlichen Gesetze beweisen, daß keine falschen, schädlichen und gefährlichen, das Staats- und Kirchenrecht bedrohenden und zerstörenden Lehren und Schriften verbreitet wurden und sie haben Schriften dieser Art, wenn sie zum Vorschein kamen, mit ihrer ganzen Macht unterdrückt? Seit den Jahren um 312 läßt sich eine enge Zusammenarbeit zwischen Kaiser und Kirche feststellen. Das bedeutet zugleich eine Zunahme dés Einflusses der weltlichen Macht auf die innerkirchlichen Angelegenheiten. Die von Traumann aufgeführten Beispiele zeigen, daß es sich in der Hauptsache um Streitigkeiten handelte, die das Gefüge der Kirche gefährdeten, zugleich aber auch um Streitigkeiten, an deren Beendigung das Reich ein besonderes Interesse haben mußte.

Die kirchliche Zensur tritt Traumann immer entgegen als zentralisiertes Handeln. Auf diesem Gebiet erscheint die Kirche in Gestalt der „Rechtskirche” als die mächtige Herrin und gewaltsame Herrscherin: „Der Zensur und ihren Wandlungen gibt die Kirche ein ihr eigenes Gesicht. Mag auch der Vorwurf, 'Erfinderin' der Zensur zu sein, sie nicht treffen können, so ist diese Seite im Leben der Kirche eine eigenartige, die sich ganz erheblich von den anderen abhebt," so Traumann ${ }^{8}$. Das Kirchenrecht fällt dabei keine Glaubensentscheidungen, es ist disziplinäres Gesetz, verpflichtet nur zu einem Tun oder Lassen, im Fall der Zensur also nur zum Nichtgebrauch. Die Definition für den Ketzer als Verbrecher heißt im Mittelalter: „Haereticus est, qui falsas vel novas opiniones gignit vel sequitur." Der Ketzer wurde auch nach Reichsgesetz bestraft, weil in dem Heiligen Römischen Reich Deutscher Nation, in dem die römisch-katholische Kirche Zwangskirche war bis zum Augsburger Religionsfrieden (1555), die Glaubenseinheit als ein Grundsatz des Reiches galt.

Dieses Verbrechen der Ketzerei im Schrifttum sollte anfangs die Zensur nur bekämpfen. Die Inquisition (seit 1227) richtete sich nicht nur gegen Personen bzw. Ketzer, aber auch gegen ketzerische Schriften". Traumann nennt den Verlauf der kirchlichen Zensurpraxis einen gleichmäßigen: „.. . er verläuft vom Zeitalter der Apostel bis zum Ende des 15. Jahrhunderts als eine repressive Zensur, gleichmäßig bis ins Jahr 1487 , in dem am 12. November die erste allgemeine päpstliche Zensurordnung erlassen wurde" 10 .

\section{Die Ausübung der Zensur durch die Kölner Universität und die kirchliche Zensur}

Die erste Vorzensur - das oben erwähnte platonische System - nach Erfindung des Buchdruckes übte die Universität Köln als Lehrstätte der Sancta Scholastica seit I479 oder 1475 aus. In Köln, wo seit dem Jahre 1466 gedruckt wurde, ist die Vorzensur rechtlich zuerst von der Universität gehandhabt worden auf Grund eines Breve von Papst Sixtus IV., das datiert ist vom I8. März ${ }^{11}$ I479. Diese päpstliche Urkunde lautet: „Wir haben euren Brief empfangen und aus diesem mit Wohlgefallen gelesen, mit welchem Eifer der Rechtgläubigkeit, mit welcher Klugheit ihr verhindert habt, daß ketzerische Schriften gelesen, gedruckt und verkauft werden . . . Damit ihr euer gutes Beginnen leichter fortsetzen könnt, verleihen wir euch das Recht und geben euch die Möglichkeit, mit kirchlichen Zensuren und anderen geeigneten Heilsmitteln gegen Drucker und Leser von Büchem dieser ketzerischen Art vorzugehen. Und weil es geschehen könnte, daß Drucker aus Furcht vor euren Maßnahmen sich an andere Orte begeben, wollen wir, daß ihr den Behörden dieser Orte diesen unseren Willen kundgebt, der überall beobachtet werden soll."

Dieses Antwortschreiben läßt, so Muckel, verschiedene Folgerungen zu. Es scheint, daß vor 1479 eine Präventivzensur von der Universität ausgeübt wurde. Dieses geht 
aus der Passage hervor: „mit welchem Eifer ihr verhindert habt, daß ketzerische Bücher gedruckt werden". Entsprechend diesen Worten mußten von der Universität Bücher vor Durcklegung auf ihren Inhalt geprüft worden sein. Einige Bücher scheinen dabei nicht das Imprimatur erhalten zu haben. Einige Daten stützen die Annahme, daß die Inquisitoren an der Universität Köln das Zensurrecht zuerst eingeführt und ausgeübt haben. Im Jahre 1479 zensurierten die beiden Kölner Professoren Gerhard von Elten und Jakob Sprenger die Schriften eines Dr. Wesalia in Mainz. Im gleichen Jahr verlieh der Papst der Universität Köln das Zensurrecht ${ }^{12}$.

Für die Zeit nach der Erfindung der Buchdruckerkunst stammt, so dennoch Eisenhardt, der erste Hinweis auf eine nicht rein kirchliche Aufsicht über gedruckte Schriften schon aus dem Jahre 1475. Aus diesem Jahr existiert ein Buch, das einen Vermerk trägt, den noch eine Reihe anderer Bücher aus den nachfolgenden Jahren aufweisen: "Admissum ac probatum ab alma matre Coloniensi". Dieser Vermerk weist auf eine inhaltliche Überprüfung des Buches vor der Drucklegung hin. Es ist, so Eisenhardt, in diesem Fall von einer Aufsicht in Gestalt der Vorzensur zu sprechen ${ }^{13}$. Der erste Prozeß gegen den Autor einer mißbilligten Schrift soll 1478 in Köln stattgefunden haben ${ }^{14}$. Von 1483 bis 1487 wurde die Zensur von der Kölner Universität nicht mehr ausgeübt.

In Rom erkannte man die Gefahr des Buchdruckes besonders in dem Lande seiner Erfindung, und Papst Innocenz VIII. erließ daher am 17. November $1487^{15}$ seine berühmte Bulle "contra Impressores Librorum Reprobatorum", in der die frühesten allgemeinen Richtlinien für die Handhabung der Zensur vorgeschrieben sind. Man kann in dieser Bulle mehrere Anordnungen feststellen, die später Angelpunkte des Pressepolizeirechts bis zur Aufhebung der mittelalterlichen Zensur geworden sind. Die Zensur wird im präventiven Sinne angeordnet. Besonders zu diesem verantwortungsvollen Amte befähigte Männer sollen die Bücher vor ihrem Drucke sorgfältig prüfen. Sie haben dafür zu sorgen, daß nichts gedruckt wird, was dem orthodoxen Glauben zuwider, gottlos oder ärgernisgebend ist. Alle Drucker haben die ihnen übergegebenen Manuskripte vor der Drucklegung bei den von den Bischöfen eingerichteten Stellen zur Zensur einzureichen.

Gedruckte Bücher sollen auf ein Verzeichnis gesetzt werden und die von den Zensoren nach diesem Verzeichn is verdammten Publikationen müssen sofort abgeliefert werden. Im Falle der Nichtbefolgung dieser Vorschrift soll der Drucker mit der „excommunicatio" und mit Geldstrafe bestraft werden. Aber nicht nur der Drucker, sondern auch diejenigen, die noch die vor diesem Erlaß gedruckten, von den Zensoren aber verworfenen Bücher lesen oder zurückbehalten, soll dieselbe Strafe treffen. Die Ungehorsamen oder Widersetzlichen, und mögen es auch Genossenschaften, Universitäten und Kollegien sein, sollen gleichfalls mit Exkommunikation, Suspension, Interdikt, Zensuren sowie anderen Sentenzen und Strafen, die auch verschärft „und nochmals verschärlt werden dürfen" und bei denen die Appellationen ausgeschlossen sein sollen, zur Beachtung dieser Vorschriften gezwungen werden. Notfalls soll der weltliche Arm angerufen werden, dem die Hälfte der von ihm beigetriebenen Strafe zufallen soll, damit er williger hilft.

Diese Bulle war insbesondere an die Bischöfe von Köln, Mainz, Trier und Magdeburg in diesen Städten wurde damals hauptsächlich gedruckt - gerichtet. Damit sollten nun von diesen Bischöfen besondere Zensurstellen eingerichtet werden. Unter diese 
Zensur fielen sämtliche Bücher, auch die „weltlichen”. Man kann an diesem Erlaß, der nirgendwo auf Widerstand stieß, bei seiner Ausführung sehen, wie sehr man in dieser Zeit gewohnt war, die Regelung aller geistigen Fragen der Kirche zu überlassen ${ }^{16}$. Es ist fraglich, ob mit dieser Neuregelung das Zensurrecht der Universität aufgehoben wurde. Das Breve von Sixtus IV. von 1479 hatte der Universität als geistlicher Zensurbehörde ein zeitlich wie örtlich unbeschränktes Recht verliehen ${ }^{17}$. Wenn sich in Köln die politischen und kirchlich-katholischen Verhältnisse in dieser Zeit fast noch vollständig deckten bei der Betrachtung der geistigen Belange, vielleicht sogar kirchliche Fragen Anstoß gaben zu weltlichen Maßnahmen, so könnte der falsche Eindruck bei der Darstellung des Entstehens und der Entwicklung der Zensur erweckt werden, daß diese Beschränkung der Druckfreiheit allein ein Ausfluß der autoritativen Machtstellung eines katholischen Kirchenregiments gewesen wäre. Die Zensur aber war keine rein katholische Maßnahme, sondern eine allgemeine Einrichtung der Zeit zur Bekämpfung und Unterdrückung gegnerischer Ansichten. Auch in protestantischen Ländern wurde die Zensur als ein solches Machtmittel ausgenutzt ${ }^{18}$.

Die Zeitenwende macht sich am Ende des 15. Jahrhunderts auch in der Handhabe der Zensur der Kirche bemerkbar ${ }^{19}$. Nicht allein, daß der erwachte Geist gegen die Kirche und ihre Institutionen nun offener hervortrat, er fand auch in der neuen Kunst ein Mittel der wirksameren und schnelleren Verbreitung. Die bisherigen Methoden der Kirche, erschienene Schriften zu kassieren, zu verbieten und zu verbrennen und nötigenfalls den Verfasser aus der Gemeinschaft des kirchlichen Verbandes zu verbannen, diese Methoden hatten zum Teil ihre Wirksamkeit verloren. Die neue Möglichkeit, mittels des Drucks eine im Verhältnis zur Vorzeit ungekannte Auflage zu verbreiten, mußte zu neuen Maßnahmen der Kirche führen. Die Zensur ist immer nur als Gegendruck zu betrachten. Das Motiv zu ihrer Einrichtung ist das Gefühl der Angst. Die Zensur ist der erste bedeutsame gesetzliche Reflex der größten Umwälzung in der christlichen Menschheit. Die Ursachen für ihr Entstehen liegen so klar wie bei keiner anderen damals von Kirche und Staat getroffenen Schutzmaßnahme bei Gefährdung der Struktur des mittelalterlichen Weltbildes. Die Zensur war nämlich ein Wall, den der mittelalterliche Mensch als solcher um sein Reich errichtete, um es vor den eine neue Zeit und Weltordnung ankündenden Stürmen, die jeden zu entwurzeln drohten, zu schützen ${ }^{20}$.

Mit der obengenannten Bulle von Innocenz VIII. (1487) „contra Impressores Librorum Reprobatorum" setzt die neue Epoche der kirchlichen Zensurgesetzgebung ein. Ein Wendepunkt der durch die Ereignisse der Zeit bedingt ist, der somit auch für die Betrachtung des Verhältnisses von Zeitung und Zensur grundlegend erscheint. Mit dieser Bulle ist der Wandel vollzogen. Die kirchliche Zensur tritt in das Stadium einer neuen Epoche, woraus ihre große Bedeutung erwächst. Mit den Worten der Zeit spricht die Kirche zu der neuen Kunst, spricht über ihre Bedeutung im allgemeinen. über ihren großen Nutzen, aber auch zugleich über die Möglichkeiten ihrer ungeahnten Schadenstiftung. Dem tritt die Kirche mit jener ganzen ihr noch zu Gebote stehenden Macht entgegen, die langsam zu verfallen scheint. Und wegen dieser ihrer Bedeutung wurde sie hier ausführlicher behandelt, während die nachfolgenden Bullen und Erlasse nur in jenen Passagen Berücksichtigung fanden, die unmittelbar themenrelevant sind.

Von hier aus geht die Entwicklung durch Jahrhunderte. Zahlreich sind die Verordnungen, sehr zahlreich die Beschlüsse, die ergangen sind. Nicht alle können hier be- 
trachtet werden. Genannt seien nur „Inter multiplices” vom 1. Juni 1501 (von Papst Alexander VI.) und „Inter solicitudines” vom 4. Mai 1515 (von Papst Leo X.); die Zeit der Reformation brachte eine Fülle von Flug- und Schmähschriften in beiden Lagern. Die Publikationen Luthers wurden durch die Bulle „Exsurge Domine” vom 15. Juni 1520 durch Papst Leo X verdammt. Dieses Verbot wurde im Jahre 1522 durch Papst Hadrian VI. in einem Schreiben an die Bevölkerung der Stadt Bamberg erneuert.

Die Unmenge der Schriften ließ bald die Unmöglichkeit der Durchführung dieser bisher erlassenen Präventivbestimmungen erkennen. Denn jene, die gegen die Kirche und ihre Institutionen, gegen den Papst und die Bischöfe, gegen den Ablass und die „gravamina” schrieben, sie gehörten ja seit dem Bruch Luthers mit der Kirche nicht "mehr zu den Gläubigen im Sinne der Kirche. Daher wandte sich die Kirche nunmehr einer neuen Maßnahme zu. Nicht mehr die Drucker wurden jetzt mit Strafen belegt, vielmehr erließ man Verordnungen, die den Gläubigen das Verbot des Lesens solcher Schriften auferlegten; gewisse Publikationen verfielen dem Verbot. Man hatte nicht mehr die Macht, gegen den Druck derartiger Objekte einzuschreiten. Aber die Anzahl der neuen Werke, der Bücher und der Schriften, die Fülle der neuen Gedanken war so unendlich groß und nicht immer der „Geist” dieser Schriften auszumachen, daß man zur Einrichtung eines Verzeichnisses solcher verbotenen Publikationen kam. Weder den Laien noch den Geistlichen war es immer möglich, den rechten Geist eines Werkes zu erkennen. So wollte die Kirche ihnen künftig behilflich sein: das war der dahinterliegende Gedanke.

Ein solches Verzeichnis verbotener Bücher hatte bereits Kaiser Karl V. im Jahre 1540 für Flandern erlassen, die Sorbonne im Jahre 1542 für Paris und im Jahre 1546 erschien ein solches Verzeichnis von der Universität Löwen. Ein Synodalbeschluß aus dem Jahre 1549, erlassen von einer Provinzialsynode zu Köln, legt den Geistlichen und den Gläubigen die Aufstellung eines derartigen Verzeichnisses und dessen Begründung dar ${ }^{21}$. Während dieser Zeit tagte bereits in Trient das Reformkonzil. Schon im Jahre 1523 hatten die in Nürnberg versammelten Stände des Reiches an Papst Hadrian VI. die Bitte gerichtet, ein allgemeines Konzil einzuberufen. Papst Clemens VII., der im Herbst des Jahres 1534 starb, wurde durch Paul III. im Pontifikat abgelöst, und dieser berief in einer Konvokationsbulle vom Jahre 1536 ein allgemeines Konzil nach Mantua. Dieses Konzil trat jedoch nicht zusammen, vielmehr wurde ein neues Treffen auf den Mai 1538 anberaumt. Erst im Jahre 1541 wurde nach diesen Versuchen wieder ernstlich an die Berufung der Bischöfe gedacht, und am 22. Mai 1542 erschien die Ankündigungsbulle.

Das Konzil selbst aber wurde erst am 13. Dezember 1545 eröffnet. Hauptgegenstände der Beratung waren die Verwerfung der Irrlehren und die Verbesserung der Kirchenzucht. Die Zusamamenkunft beschäftigte sich in ihren Sitzungen sehr eingehend mit den HI. Schriften, mit dem Bücherdruck und der Bücherzensur. Schon in der 4. Sitzung, am 18. April 1546, erging ein Beschluß über die kanonischen Schriften und ein anderer über die Ausgabe und den Gebrauch der HI. Schriften. In diesem Beschluß wurde den Druckern zur Pflicht gemacht, nicht ohne Erlaubnis der geistlichen Vorgesetzten die Bücher der Hl. Schrift und Anmerkungen und Erläuterungen dazu ohne den Namen des Verfassers zu drucken und anderwärts gedruckte Bücher dieser Art zu verkaufen. 
In der 18. Sitzung, am 26. Februar 1562, erging ein weiterer Beschluß über die Auswahl der Bücher. Sodann beschloß das Konzil in der 25. Sitzung, am 4. Dezember 1563 , eine Verordung „vom Verzeichnis der Bücher und von dem Katechismus, dem Brevier und dem Messbuche”. In diesem Beschluß wird festgestellt, daß die Beratungen der von Papst Pius IV. eingesetzten Kommission beendet seien, daß „aber doch wegen Verschiedenheit und Menge der Bücher vom Kirchenrate nicht genau und füglich darüber abgeurteilt werden kann”; es wird dann beschlossen, „daß dasjenige, was von ihnen zustande gebracht worden ist, an den heiligsten römischen Papst gewiesen werden soll, damit es nach dessen Urteil und Autorität beendigt und bekannt gemacht werde". Das Ergebnis der Arbeit dieser Kommission waren die 10 Regeln über die verbotenen Bücher: „De libris prohibitis / regulae decem”. Diese wurden von Papst Pius bestätigt und durch das Breve „Dominici gregis custodiae”vom 24. März $1564^{22}$ veröffentlicht. Die 10. Regel ist jene, die sich mit den Buchdruckern beschäftigt, sie reicht bis in Einzelheiten. Sie ist bis in die nachfolgenden Jahrhunderte in Kraft gewesen und bildete die Grundlage für die späteren Gesetzgebungen auf dem Gebiete des Drucks; hier der volle Wortlaut ${ }^{23}$ :

„Beim Drucke der Bücher und anderer Schriften soll dasjenige beobachtet werden, was in dem lateranensischen Konzil unter Leo X. in der 10. Sitzung verordnet wurde. Wenn deswegen in der erhabenen Stadt Rom irgend ein Buch gedruckt werden soll, so muß dasselbe durch den Vikar des Papstes und den Magister des hl. Palastes, oder durch andere von unserem hl. Herrn zu bestellende Person zuerst geprüft werden. An anderen Orten aber soll diese Genehmigung und Prüfung dem Bischofe oder jemandem Anderen, der, das Buch oder die Schrift, die gedruckt werden soll, kennend, von demselben Bischofe dafür zu bestellen ist, und dem Inquisitor ketzerischer Verderbtheit der Stadt oder der Diöcese, in welcher der Druck stattfinden soll, zustehen, und durch Bekräftigung mit ihrer Hand, vermittelst eigener Unterschrift, unentgeltlich und ohne Verzögern genehmigt werden, unter der in dem nämlichen Beschlusse enthaltenen Strafen und Zensuren, jedoch mit Hinzufügung der Vorschrift und Bedingung, daß ein authentisches Exemplar des zu druckenden Buches, von der Hand des Autors unterschrieben, bei dem Zensor zurückbbleiben soll. Diejenigen aber, welche handschriftliche Bücher, ehe sie vorher geprüft und genehmigt sind, bekanntmachen, müssen, nach dem Ermessen der Väter, den nämlichen Strafen, wie die Drucker, unterworfen, und diejenigen, die sie besitzen und lesen, sollen, wenn sie die Verfasser nicht angeben, für die Verfasser selbst gehalten werden. Die Genehmigung solcher Bücher selbst soll aber schriftlich erteilt, und authentisch dem geschriebenen oder dem gedruckten Buche angesetzt werden, und die Genehmigung und Prüfung und das übrige unentgeltlich geschehen. Überdies soll in allen Städten und Diöcesen die Häuser und die Orte, wo die Buchdruckerkunst geübt wird, und die Bibliotheken verkäuflicher Bücher, von durch den Bischof oder durch dessen Vikar dazu zu bestellenden Personen, und auch von dem Inquisitor ketzerischer Verderbtheit öfters visitiert werden, auf daß nichts Verbotenes weder gedruckt, noch verkautt, noch behalten werde. Alle Buchhändler und jegliche Verkäufer von Büchern sollen in ihren Bibliotheken ein Verzeichnis der verkäuflichen Bücher, die sie halten, mit der Unterschrift der genannten Personen besitzen und ohne Erlaubnis derselben dazu Abzuordnenden, dürfen sie unter der Strafe des Bücherverlustes und anderen, nach dem Gutachten der Bischöfe oder Inquisitoren zu verhängenden Strafen, keine anderen Bücher haiten oder verkaufen, oder auf was immer für eine Weise verabfolgen lassen. Die Käufer aber, die Leser oder die Drucker, sollen nach dem Gutachten ebenderselben bestraft werden. Wenn jemand was immer für Bücher in eine Stadt einbringt, so sei er gehalten, den nämlichen $\mathrm{Ab}$ zuordnenden Anzeige davon zu machen, oder falls für Waren solcher Art ein öffentlicher Ort bestimmt ist, so sollen die Beamten dieses Ortes den vorgemeldeten Personen anzeigen, daß Bücher eingebracht worden sind. Niemand aber erkühne sich, ein Buch, das er selbst oder ein anderer in die Stadt eingebracht hat, jemandem zu Lesen zu übergeben, oder auf irgend eine 
Weise zu veräußern, oder zu leihen, ehe er es vorgewiesen und von den abzuordnenden Personen die Erlaubnis dafür erhalten hat, es sei denn, daß das Buch schon als ein allen Erlaubtes notorisch bekannt ist. Das nämlich werde auch von allen Erben und den Testamentsexekutoren beobachtet, so daß sie die von den Verstorbenen zurückgelassenen Bücher, oder ein Verzeichnis derselben den abzuordnenden Personen vorlegen und von ihnen die Erlaubnis erhalten sollen, ehe sie dieselben gebrauchen, oder auf was immer für eine Weise an andere übertragen dürfen. Bei diesem allem und jeglichem aber soll nach dem Gutachten ebenderselben Bischöfe oder Inquisitoren, die Strafe des Bücherverlustes, oder eine andere je nach Beschaffenheit der Widersetzlichkeit oder des Vergehens, angeordnet werden.

Hinsichtlich derjenigen Bücher aber, welche die abgeordneten Väter geprüft, oder gereinigt, oder zur Reinigung übergeben, oder unter gewissen Bedingungen wieder zu drucken erlaubt haben, sollen sowohl die Buchhändler als die anderen dasjenige, was bekannt ist, das jene verordnet haben, beobachten. Den Bischöfen oder Inquisitoren stehe es jedoch gemäß ihrer Vollmacht frei, auch diejenigen Bücher, die nach diesen Regeln erlaubt scheinen, zu verbieten, sofern sie dies in ihren Reichen oder Provinzen oder Diöcesen für ersprießlich erachten. Übrigens hat der Geheimschreiber der abgeordneten Väter die Namen sowohl der Bücher, die von denselben Abgeordneten gereinigt worden sind, als auch derer, die jenen diese Amtsvorrichtung aufgetragen haben, auf Befehl unseres heiligsten Herrn schriftlich dem Notar der heiligen allgemeinen römischen Inquisition zu übergeben.

Endlich aber wird allen Gläubigen befohlen, daß sich niemand erkühnen soll, gegen die Vorschrift dieser Regel oder das Verbot dieses Verzeichnisses irgendwelche Bücher zu lesen oder zu besitzen. Und wenn jemand Bücher von Ketzern oder Schriften von was immer einem Verfasser, welche wegen Ketzerei oder des Verdachtes einer falschen Glaubenslehre verdammt und verboten sind, liest oder besitzt: so verfalle er sogleich der Strafe der Exkommunikation. Wer dagegen Bücher, die unter einem anderen Namen verboten sind, liest oder besitzt, der soll nebst der Verschuldung einer schweren Sünde, mit welcher er behaftet wird, nach dem Urteile der Bischöfe strenge bestraft werden."

Zugleich mit dieser Breve wurde der „Index” durch Papst Pius IV. veröffentlicht und zugleich fand er seine Zustimmung. Diese Regeln - und insonderheit die letzte - beziehen sich nicht nur auf Bücher, sondern ganz allgemein auf „Schriftwerke”. Sie ist bis zur Neuregelung der gesamten Büchergesetzgebung durch Papst Leo XIII. (1900) die Grundlage geblieben, und die Strafandrohung ist hier noch verschärft gegenüber den bisher geltenden Bestimmungen. Denn im Index wird erstmals die „Verschuldung einer schweren Sünde" erwähnt. Jene Kommission, die während des Tridentinums den Index und dessen Regeln bearbeitet hatte, wurde unter Pius V. (1571) als Kongregation unter dem Namen „Congregatio Indicis librorum prohibitorum” zur ständigen Einrichtung erhoben. Papst Sixtus V. umgrenzte ihren besonderen Aufgabenkreis (22. Januar 1587).

Das Konzil zu Trient, von dem neue Kräfte in die alte Kirche strömten, hatte somit in Bezug auf den Druck von Schriftwerken eine eigene Behörde der Zensur geschaffen. Nur in der 10. Regel waren allgemeine Grundsätze festgelegt und Bestimmungen aufgestellt. Schon wenige Jahre nach Beendigung des Konzils, noch bevor durch die genannten Päpste die Umwandlung dieser Kommission in eine ständige Behörde vollzogen war, erschien der erste päpstliche Erlaß gegen die „libelli famosi”, worunter nach den Schilderungen, die Papst Pius V. in seinem Breve von 1572 „Romani pontificis procidentia" davon macht, die ersten Zeitungen, die damals auftauchten, zu verstehen sind.

Es handelte sich um „Briefzeitungen”, die als Vorläufer der Wochenzeitungen Erwähnung fanden. Die erste kirchliche Zeitungszensur fängt, so Traumann ${ }^{24}$, mit dem hier 
genannten Breve von 1572 an. Die Beweglichkeit der Zeitung gegenüber der Schwerfälligkeit des Buches machte die Periodica umso bedeutsamer, da der Wirksamkeitsradius in der Öffentlichkeit einer volkstümlichen, meist in deutscher Sprache geschriebenen Zeitung, die sich mit der Wiedergabe jedermann interessierender Geschehnisse und aktueller Fragen beschäftigte, gèwöhnlich größer sein konnte, als der eines fachwissenschaftlichen, dazu meist lateinischen Buches. Die Zeitung beschäftigte sich naturgemäß weniger mit kirchlich-religiösen als mit staatlich und städtisch politischen Belangen ${ }^{25}$.

In konsequenter Weiterbildung der Bestimmung von 1572 hätte von hier aus die Zeitungszensur mit der weiteren Entwicklung über die Wochenzeitung zur Tageszeitung kommen müssen. Im Gleichschritt mit der Aufwärtsentwicklung der Zeitung hätte von hier aus die Ausbildung und die Fortbildung eines kirchlichen „Presserechts” kommen können, doch dem ist nicht so. Vielmehr folgte in späteren Zeiten dem ersten Verbot nur immer ein spezielles Verbot für einzelne solcher „libelli”. Es wird bei diesen späteren Verordungen und Verwerfungen nicht unterschieden zwischen ,libelli” in dem hier aufgezeigten Sinne. Daher wird diese Entwicklung hier nicht weiter verfolgt, zumal ja nach diesem ersten Ansatzpunkt einer echten Zeitungszensur im Gegensatz zur Bücherzensur die erstere mit der letzteren immer parallel verlief.

Noch im tridentinischen Jahrhundert erschien eine Neuausgabe des Index und damit im Zusammenhang eine Neuordnung der Rechtsbestimmungen. Papst Clemens VIII. übernahm von Sixtus V. einen neuen Entwurf des Index, eine Verschärfung der Normen trat ein. Dieses Papier war datiert vom 17. Mai 1593, wurde aber nicht veröffentlicht. Erst unter dem 27. März 1596 erschien der neue Index mit einer ,instructio adiecta”, in der die Bestimmungen der zehnten Regel eine wesentliche Verschärfung erhielten. Die Drucker und Händler von Venedig legten beim Papst Beschwerden gegen die Erschwerung ein und erwirkten durch Mitteilung vom 14. Dezember 1595 die Milderung einiger Bestimmungen. Diese Milderung besaß jedoch nur Rechtskraft für die Drucker und Buchhändler in Venedig, im allgemeinen blieb die Verschärfung bestehen. In Nr. 8 der Instruktion von Papst Clemens VIII. (1593/1596) wurde die Regel 10 von Trient folgendermaßen abgeändert ${ }^{26}$ :

„Was dabei auszumerzen ist, sind häretische, irrige, nach Häresie schmeckende, Ärgernis erregende, fromme Ohren beleidigende, gewagte, schismatische, aufrührerische und gotteslästerliche Sätze oder Behauptungen. Ferner sollen solche ausgemerzt werden, welche gegen den Ritus und die Sakramente und Gewohnheiten der römischen Kirche Neuerungen einführen. Neue, von den Häretikern ersonnene und auf Täuschung berechnete profane Ausdrucksweisen. Zweifelhafte, doppelsinnige Wörter, wodurch die Leser vom rechten, katholischen Sinne ab- und zu verwerfenden Meinungen verleitet werden können. Worte der HI. Schrift, untreu wiedergegeben, oder aus Übersetzungen der Häretiker geschöpft, es sei denn daß sie zu deren Widerlegung gebraucht werden. Worte der Hl. Schrift, zu profanen Zwecken gottlos mißbraucht, oder zu einem den katholischen Vätern und der einstimmigen Meinung der Kirchenlehrer widerstreitenden Sinne verdreht. Dann ehrende Bezeichnungen und Lobeserhebungen auf Härtiker. Überdies alles, was nach Aberglauben, Zauberei, Wahrsagerei schmeckt. Alles, wodurch die menschliche Willensfreiheit dem Schicksal, trügerischen Wahrzeichen oder dem heidnischen Zufall untergeordnet wird. Alles, was nach Heidentum schmeckt. Alles, wodurch der gute Ruf des Nächsten, besonders der Geistlichen und der Fürsten verletzl, den guten Sitten und der christlichen Zucht zu nahe getreten wird. Alle Behauptungen gegen die Freiheit, die Immunität und Ju risdiktion der Kirche. Alles, was aus den Gesetzen, Sitten und Beispielen der Heiden geschöpft, unter dem falschen Namen der Staatsräson, eine tyrannische, dem evangelischen und christlichen Gesetze widerstrei- 
tende Politik befördert. Beispiele, welche die Geistlichen, die Riten, die Orden, den Stand, die Würde und die Personen der Religionen verletzen. Späße und Anekdoten, zum Schaden und gegen den Ruf anderer vorgebracht. Endlich alles Schlüpfrige, was die Sitten verderben kann.”

Nach diesen allgemeinen Bestimmungen werden in den Nummern 9, 10, 11 und 12 besonders scharfe und harte Vorschriften für die Buchdrucker und Buchhändler erlassen:

„Kein Buch soll gedruckt werden, außer mit Angabe des Tauf- und Schreibnamens, des Vaterlandes des Verfassers, oder mindestens desjenigen, der den Druck approbiert hat."

„Kein Buch soll gedruckt werden ohne Angabe des Druckers, des Druckortes und der Jahreszahl."

"Von jedem in Druck zu gebenden Buche soll eine Anschrift dem Bischof oder Inquisitor übergeben, und nach der Durchsicht zurückbehalten werden; und kein gedrucktes Buch soll verkauft werden, bevor es durch den dafür aufgestellten bischöflichen Beamten mit jener Abschrift verglichen und die Erlaubnis zum Verkaufe gegeben worden ist."

„Die Buchdrucker und die Buchhändler sollen vor dem Bischof oder Inquisitor eidlich versichern, ihr Geschäft katholisch, redlich und treu zu verwalten, und den betreffenden kirchlichen Vorschriften zu gehorchen, auch keinen von der Häresie angesteckten Gehilfen dabei zu verwenden."

Die Betrachtung der ersten Zeitungszensur - Verwerfung der „libelli famosi” - zeigt, $\mathrm{da} \beta$ in Weiterbildung der Trienter Bestimmungen die Zensur der Zeitung immer im Schritt mit der Büchergesetzgebung verläuft, ja, daß sogar die anderen Schriftwerke nie eigens hervorgehoben werden, sondern daß die Bestimmungen für die Zensur von Büchern immer Geltung haben, auch für Periodica ${ }^{27}$.

\section{Die kaiserliche Aufsicht über Buchdruck, Buchhandel und Presse}

Ulrich Eisenhardt hat in seiner Bonner Habilitationsschrift die Oberaufsicht über das Bücher- und Pressewesen dargestellt, die im Heiligen Römischen Reich Deutscher Nation der Kaiser und seine Organe ausübten. Im Vordergrund analysiert er die Entwicklung des Rechts, soweit es Buchdruck, Buchhandel und Presse betrifft, und seine Anwendung in der Praxis seit Ende des 15. Jahrhunderts. Dabei beschränkt er sich auf die Darstellung der Evolution, die das weltliche Recht, soweit es das Bücher- und Pressewesen betrifft, genommen hat. Nachfolgend sollen hier die Hauptlinien der Veröffentlichung von Eisenhardt referiert werden. Er schildert die Entwicklung des Systems der Aufsicht im 16. Jahrhundert, um anschließend das Bücherregal, die „privilegia impressoria", die Praktiken der Vorzensur sowie die kommunikationspolitische Überwachung religiöser Schriften im Zeitalter der Glaubenskämpfe vor Augen zu führen.

Das System der Überwachung auf dem Gebiete des Bücher- und Pressewesens, wie es sich im 16. Jahrhundert herausgebildet und im 17. und 18. Jahrhundert verfestigt hatte, beruhte auf einer Vielzahl reichsgesetzlicher Bestimmungen. Die Art der Rechtsquellen, in denen sich diese Vorschriften finden, ist recht verschieden, Reichspolizeiverordnungen, die 'Constitutio Criminalis Carolina', der Religionsfrieden von 1555, der Westfälische Frieden von 1648 und die kaiserlichen Wahlkapitulationen, die erst seit 1653 Befunde bringen. Außerdem existieren eine Menge kaiserliche Edikte und Patente - in der hier relevanten Periode ist jene von 1608 wohl die wichtigste - und interner Anweisungen, die sich mit dieser Materie befassen. Die reichsgesetzlichen Bestimmungen bildeten die Rechtsgrundlage für das Einschreiten der kaiserlichen Behörden und die von diesen verhängten Maßnahmen. 
Die erste Nachricht über das Tätigwerden eines kaiserlichen Organs auf dem Gebiete des Bücherwesens stammt aus dem Jahre 1496. In diesem Jahr bestellte Kaiser Maximilian I. einen Doktor der Rechte mit dem Namen Oessler in Straßburg zum 'Generalsuperintendenten des Bücherwesens in ganz Teutschland'. Das erste - bisher nachweisbare - kaiserliche Bücherverbot stammt aus dem Jahre 1512. Es handelt sich dabei um ein Mandat Maximilians I., mit dem er die „den Juden günstigen, dem Christenglauben nachteiligen Bücher" des Humanisten und Juristen Johannes Reuchlin verbot $^{28}$. Als zweites bisher bekanntes Verbot auf Reichsebene, das erlassen wurde, ohne daß es entsprechende reichsgesetzliche Bestimmungen gab, gilt das Verbot der Schriften Luthers, das am 27. März 1521 öffentlich verkündet wurde. Dieses Verbot bildete eine Vorstufe zu dem bekannten Edikt vom 8. Mai 1521, das nicht nur Luthers, sondern auch alle anderen mit der herrschenden christlichen Lehre nicht übereinstimmenden Schriften verbot ${ }^{29}$.

Die Aufteilung des Reiches in Territorien und die damit verbundene Aufspaltung von Rechten zwischen Kaiser und Landesherrn fand ihren Niederschlag auch in dem Recht, welches das Bücher- und Pressewesen betraf. Das Recht und die Pflicht, eine Vorzensur über sämtliche in den Druck gehenden Schriften auszuüben, stand den „landesherrlichen Ortsobrigkeiten”, d.h. denjenigen Institutionen zu, deren sich die Landesherrn zur Verwaltung ihrer Länder unter Aufsicht des Landesherrn bedienten. Die Vorzensur als solche wurde bereits mit dem kaiserlichen Edikt vom 8. Mai 1521 für alle in den Druck gehenden Schriften eingeführt. Verfestigt wurde sie durch den Reichsabschied von Speyer aus dem Jahre 1529. Es durfte keine Schrift gedruckt werden, die nicht zuvor durch „von jeder Oberkeit dazu verordnete verständige Personen besichtiget" und zum Druck zugelassen war. Bot die zensierte Schrift zu Beanstandungen Anlaß, hatte die zuständige „Obrigkeit” den Autor, Drucker und Verkäufer zu bestrafen. Vervollständigt wurde dieses System schon ein Jahr später durch den Reichsabschied von Augsburg. Diejenigen landesherrlichen Ortsobrigkeiten, die ihren Verpflichtungen, die Vorzensur streng auszuüben und gegen die Verfasser, Drucker und Verkäufer nichtgesetzmäßiger Schriften vorzugehen, nicht nachkamen, sollten sich damit selber strafbar gemacht haben.

Der kaiserliche Fiskal beim Reichskamme rge richt hatte die Aufgabe, die Betroffenen zu ermitteln und sie hart bestrafen zu lassen. Näher präzisiert wurde der bereits geschaffene Rechtszustand durch die Reichspolizeiordnung von 1548 , ohne daß die bestehenden $\mathrm{Zu}$ ständigkeiten verändert oder erweitert wurden. Eine Verschärfung brachte der Reichsabschied von Speyer aus dem Jahre 1570. Alle Winkeldruckereien sollten ab sofort abgeschafft sein. Druckereien durften nur noch in Reichsstädten und solchen Orten unterhalten werden, in denen ein Fürst residierte oder in denen es eine Universität gab. Auf diese Weise war es einfacher, die zum Druck gelangenden Schriften zu kontrollieren. Außerdem wurde den Reichsständen zur Pflicht gemacht, die auf ihrem Gebiet befindlichen Druckereien ohne Vorwarnung zu „visitieren”. Kamen sie dieser Visitationspflicht nicht nach, sollte eine von kaise rlichen Organen zu verhängende Strafe fällig werden.

Noch einen Schritt weiter ging die Reichspolizeiordnung von 1577. Sie sah vor, daß dann, wenn die zuständigen Institutionen der Landesherrn nicht oder nicht scharf genug gegen Verfasser, Drucker oder Verbreiter verbotener Schriften vorgingen, die kaiserlichen Organe selbst berechtigt sein sollten, sich des betreffenden Falles anzunehmen. Das bedeutete, der Kaiser und seine Organe konnten von sich aus direkt 
Bücher konfiszieren und die Täter bestrafen, wenn sie der Meinung waren, daß ein Verstoß gegen die Reichsgesetze vorlag und die zuständigen Behörden eines Landesherrn nicht eingegriffen hatten.

Dieses in der zweiten Hälfte des 16. Jahrhunderts verfestigte System blieb im wesentlichen bis zum Ende des Reiches im Jahre 1806 bestehen. Wichtige Änderungen erfolgten nicht mehr. Es war also Sache der Landesherren, darauf zu achten, daß in ihren Territorien keine unzensierten Schriften hergestellt und verbreiten wurden. Ihnen oblag auch die Bestrafung derjenigen, die gegen die Reichsgesetze verstoßen hatten. Recht und Pflicht des Kaisers dagegen war es, darüber zu wachen, daß die Landesherren und ihre Behörden die ihnen durch die Reichsgesetze auferlegten Verpflichtungen erfüllten. Um dem Reichsrecht zur Durchsetzung zu verhelfen, konnte der Kaiser säumige landesherrliche Behörden und sogar Landesherren selber bestrafen und notfalls einen gerade anstehenden Fall durch seine eigenen Organe verfolgen lassen. Der Kaiser übte somit die Oberaufsicht über das Bücher- und Pressewesen im gesamten deutschen Reich aus. Zur Wahrnehmung dieses Aufsichtšrechts bediente der Kaiser sich im wesentlichen seines Reichshofrates - des in Wien residierenden kombinierten Justiz- und Verwaltungsorgans, bei dem die Fäden aus dem gesamten Reich zusammenliefen -, der Bücherkommission in Frankfurt a.M. und seiner Fiskale ${ }^{30 .}$

Die von 1524 bis 1648 entstandenen reichsgesetzlichen Bestimmungen, die eine Handhabe gegen den Druck und die Verbreitung mißliebiger Schriften bieten sollten, sind von Eisenhardt ${ }^{31}$ ausführlich beschrieben worden. Die für das Bücher- und Pressewesen wichtigsten Vorschriften und Bestimmungen enthalten der Reichsabschied von Speyer (1526) sowie jene von Speyer (1529) und Augsburg (1530). Im Augsburger Reichsabschied tritt zum ersten Mal deutlich zutage, daß der Kaiser nicht nur die oberste Aufsicht über das Gebiet des Bücher- und Pressewesens ausübte, sondern auch über die Macht verfügte, dieses Aufsichtsrecht den Reichsständen gegenüber durchzusetzen. Die kaiserlichen Fiskale sollten gegen solche landesherrlichen Behörden vorgehen, die ihrer Aufsichtspflicht nicht nachkamen; das Reichskammergericht hatte die betreffenden Mitglieder dieser Behörden zu bestrafen, wie bereits oben erwähnt wurde. Weitere Vorschriften usw, enthalten der Reichsabschied von Worms (1535), das „Edikt und ewig Gesetz” für Flandern, das Karl V. am 20. September 1540 erließ und auch in Deutschland Verbreitung fand, die Reichsabschiede von Regensburg (1541), Nürnberg (1542), die Reichspolizeiordnung (1548) und der 1555 auf dem Reichstag zu Augsburg beschlossene Religionsfrieden, der Kreistagsabschied von Erfurt („Erfurter allgemeiner Reichs-Craissabschied”). Neu und besonders wichtig ist, daß in diesem Abschied zum ersten Mal ausdrücklich Zeitungen erwähnt werden.

Die umfassendste Vorschrift des 16. Jahrhunderts auf dem Gebiete des Bücher- und Pressewesens enthält die letzte Polizeiordnung des Reiches, die 1577 vom Frankfurter Reichsdeputationstag verabschiedet wurde. Titel XXXV dieser Polizeiordnung faßt im wesentlichen noch einmal zusammen, was in den zuvor erlassenen Reichsgesetzen angeordnet worden war. Im Mittelpunkt steht das Verbot solcher Schriften, die „der christlichen allgemeinen Lehre und zu Augsburg aufgerichteten Religionsfrieden ungemäß und widerwärtig oder zu Unruhe und Weiterung Ursache geben". Hier wurde also dem durch den Augsburger Religionsfrieden geschaffenen Zustand der Reichsverfassung Rechnung getragen. Den kaiserlichen Organen wurde ausdrücklich das Recht bestätigt, selbst gegen Buchdrucker, Händler oder Käufer vorzugehen, wenn landesherrliche Behörden das versäumten. 
Auch der Vertrag zum Westfälischen Frieden enthält eine Bestimmung, die für das Bücher- und Pressewesen von großer Bedeutung war. Artikel V $\$ 50$ bestimmte, daß solche Schriften verboten sein sollten, die den Passauer Vertrag, den Religionsfrieden von 1555 oder die Vorschriften des Westfälischen Friedens selbst angriffen, in Zweifel zogen oder gegenteilige Behauptungen daraus abzuleiten versuchten. Die landesherrlichen Obrigkeiten wurden verpflichtet, für die Befolgung dieser Vorschrift Sorge zu tragen. Die Gesetzesstelle war also insbesondere auf das religiöse Schrifttum abgestellt. Die Bestimmung hatte besonderes Gewicht, weil sie in einem sogenannten Reichsgrundgesetz - d.h. in einem der Gesetze, welches für die Verfassung des Reiches die Grundlage bildeten - verankert war. Tatsächlich wurde sie in der Praxis des 17. und 18. Jahrhunderts sehr oft angewandt, indem Maßmahmen auf dem Gebiete des Bücher- und Pressewesens auf diese Vorschriften des Westfälischen Friedens gestützt wurden.

Quelle der kaiserlichen Machtfülle ${ }^{32}$ auf dem Gebiete des Bücher- und Pressewesens war das kaiserliche Bücherregal: ein Hoheits- oder Majestätsrecht, das ein Regent ohne Mitwirkung eines Mitregenten oder von Ständen ausüben konnte. Wann das kaiserliche Bücherregal entstanden ist, läßt sich nicht nachweisen. Sein Hoheitsrecht auf dem Gebiete des Bücher- und Pressewesens dürfte der Kaiser spätestens 1496 zum ersten Mal ausgeübt haben. Zweifelhaft ist, ob dem Herrscher nach der Entwicklung der Reichsgesetzgebung im 16. Jahrhundert das Bücherrregal noch allein zustand, oder ob er einen Teil seiner Hoheitsrechte aus diesem Bereich auf die Landesherren übertragen hatte. Es ist, so Eisenhardt, davon auszugehen, daß dem Kaiser das Bücherregal nicht ungeteilt zustand. Ein Teil der Hoheitsrechte auf dem Gebiete des Bücher- und Pressewesens, wie z.B. das Recht, eine Vorzensur auszuüben, war im Laufe der Zeit auf die Landesherrn übergegangen. Jedenfalls verlieh das ihm zustehende Bücherregal dem Kaiser das Recht, die Oberaufsicht im gesamten Reich auszuüben.

Das Bücherregal verlieh dem Kaiser auch das Recht, Druckprivilegien (privilegia impressoria) zu erteilen. Privilegia impressoria verleihen, heißt „verbieten, daß gewisse Bücher, innerhalb gewisser Zeit nicht ohne des Privilegie rten Willen und zu dessen Schaden sollen nachgedruckt oder die anderwärts nachgedruckten Exemplarien innerhalb des deutschen Reiches verkauft werden" ${ }^{33}$. Solche Privilegien wurden für jede Art von Druckschriften - also Bücher, Zeitschriften, Zeitungen - sowie über Kalender, Bilder und Noten erteilt. Mit dem privilegium wurde der Begünstigte vor dem Nachdruck des Werkes, über das er ein Vorzugsrecht erworben hatte, geschützt. Ein privilegium impressorium konnte dem Verfasser einer Schrift, dem Buchdrucker oder einem Buchhändler verliehen werden, es war erblich.

Die Untersuchung von Eisenhardt ${ }^{34}$ über die Anwendung der verschiedenen reichsgesetzlichen Bestimmungen durch die kaiserlichen Aufsichtsorgane und die Gerichte im 16., 17. und 18. Jahrhundert zeigt, daß den einzelnen Reichsgesetzen eine unterschiedliche Bedeutung zugemessen worden ist. In der Praxis des 16. und 17. Jahrhunderts spielten der Reichsabschied von 1570, die Reichspolizeiordnung von 1577 und der 1555 geschlossene Religionsfriede die größte Rolle. Häufig wurden auch die Reichspolizeiordnung von 1548 und die Constitutio Criminalis Carolina angewandt. Die Reichspolizeiordnung von 1548 und 1577 und der Westfälische Friede boten die vor 1648 in Kraft getretenen reichsgesetzlichen Bestimmungen. Auf Grund der Häufigkeit ihrer Anwendung in der Praxis waren es die Rechtsgrundlagen, auf die sich das 
System der Überwachung auf dem Gebiete des Bücher- und Pressewesens im wesentlichen stützte ${ }^{35}$. Es bleibt festzuhalten, daß auf diesem Gebiet niemals versucht worden ist, neues Recht an die Stelle des alten zu setzen. Seit 1524 haben alle reichsgesetzlichen Bestimmungen nur Ergänzungen und Erweiterungen des bereits bestehenden Zustandes gebracht.

Gegenstand der Überwachung ${ }^{36}$ durch die Organe des Reiches und der Landesherrn waren nach den Reichsgesetzen sämtliche Druckerzeugnisse, also Bücher, Zeitungen in jeder Form, Noten, Kupfer- und andere Stiche, sowie Karten und Kalender. Die Überwachung, in erster Linie die Vorzensur, bezog sich auf alle Druckschriften ohne Ansehen des Inhalts. So mußten selbst die einfachsten Schulbücher die Vorzensur passieren, ehe sie gedruckt werden durften. Was für Schulbücher galt, war gleichermaßen auch für die Bücher verbindlich, die von Studenten benutzt wurden. Auch wissenschaftliche Werke mußten vor dem Druck der Zensur vorgelegt werden, und zwar nicht nur solche geisteswissenschaftlichen Inhalts; auch naturwissenschaftliche und medizinische Werke unterlagen der Kontrolle. Besonderes galt für die Zensur von Zeitungen und Wochenblättern.

Abgesehen davon, daß sie von den landesherrlichen Behörden überwacht wurden, mußte der Herausgeber dann, wenn er ein kaiserliches privilegium impressorium für eine Zeitung besaß, von jeder erscheinenden Nummer 18 Exemplare an den Reichshofrat einsenden. Eine entsprechende Verpflichtung wurde dem Begünstigten schon in dem Privilegienbrief auferlegt. Versäumte er die Abgabe der 18 Exemplare, ging er des privilegium verlustig. Neben den Druckerzeignissen erstreckte sich die Kontrolle auch auf „Abgüsse” - aus Gips oder anderem Material - und „Schnitzwerke”. Eisenhardt hat darzustellen versucht, welche Schriften bei einer objektiven Auslegung der Reichsgesetze verboten waren und eine Konfiskation der Exemplare sowie eine Bestrafung der Beteiligten nach sich ziehen mußten. Er nennt religiöse, politische, Schmäh- und gegen die guten Sitten verstoßende Schriften ${ }^{37}$.

Von den Anfängen einer Aufsicht über das Bücher- und Pressewesen am Ende des 15. bis zum beginnenden 19. Jahrhundert verschob sich der Schwerpunkt der Überwachung erheblich. Zunächst richtete sich das Augenmerk fast ausschließlich auf Schriften mit religiösem Inhalt. Oberstes Ziel war es, alle Publikationen, die in irgendeiner Weise nicht mit der christlichen Lehre in Einklang standen, zu unterdrücken. Mit Beginn der Reformation änderte sich das Ziel der Aufsichts- und Verbotsmaßnahmen insofern, als nun in erster Linie die publizistischen Angriffe gegen die katholische Kirche und die Autorität und die Person des Papstes abgewehrt und einer Verbreitung der neuen Lehre durch ein Verbot dazu geeigneter Schriften vorgebeugt werden sollte. Auch nach dem mühsam errungenen Religionsfrieden von 1555, dem die Reichspolizeiordnung von 1577 noch einmal für das Bücher- und Pressewesen Rechnung trug, spielte die Verfolgung solcher Schriften, die Gedankengut der Reformation enthielten, eine besonders große Rolle.

Viele Aufsichtsorgane wurden über lange Zeit hinweg als Instrument der Gegenreformation tätig. Doch schon bald wurde die Wahrung des Religionsfriedens zum Hauptzweck der Überwachung. Jede Schrift, die Angriffe gegen eine der großen zugelassenen Konfessionen enthielt, sollte verboten und ihre Verbreitung verhindert werden. Daneben wurden auch Schriften nichtreligiösen Inhalts scharf überwacht. Eine Verlagerung des Schwerpunktes der Observanz über religiöse und politische Schriften 
bahnte sich erst in der zweiten Hälfte des 18 . Jahrhunderts an ${ }^{38}$. Emotionen, so Eisenhardt, haben bei der Beurteilung und Zensur sowohl der religiösen als auch der politischen Schriften stets eine große Rolle gespielt. Diese Emotionen waren im religiösen Bereich so stark, daß sie sich selbst in der Sekundärliteratur in einer auffälligen Weise niedergeschlagen haben ${ }^{39}$.

Eine Reihe von Reichsorganen übte die Oberaufsicht über das Bücher- und Pressewesen aus. Die bedeutendsten unter ihnen, nämlich die Bücherkommission in Frankfurt und der Reichshofrat in Wien, waren kaiserliche Organe. $\mathrm{Zu}$ den übrigen Institutionen, die mit dem Bücher- und Pressewesen befaßt waren, zählten das Reichskammergericht und der Reichstag. Außerdem spielte der Kurfürst von Mainz als Erzkanzler des Reiches eine wesentliche Rolle ${ }^{40}$. Darüber, wann die kaiserliche Bücherkommission in Frankfurt gegründet worden ist, sind die Meinungen geteilt (1569 oder zehn Jahre später) ${ }^{41}$. Eisenhardt entscheidet sich für 1597 , denn in diesem Jahr wurde sie zu einer ständigen Einrichtung. Aus den auf 1597 folgenden Jahren existieren eine Reihe von Nachrichten über die umlangreiche Tätigkeit der Bücherkommission.

Sobald die Kommission zu einer ständigen Einrichtung geworden war, wurde es schnell zur Gewohnheit, daß der kaiserliche Kammergerichtsfiskal kraft Amtes auch als Mitglied der kaiserlichen Bücherkommission galt. Der Fiskal hielt sich allerdings nur während der beiden Jahresmessen in Frankfurt auf, während das andere Mitglied der Kommission ständig in Frankfurt residierte. Hinsichllich der Besetzung dieses Amtes wurde es Brauch, daß es - sieht man von wenigen Ausnahmen ab - von katholischen Geistlichen, die in der Regel in Frankfurt Pfarrer waren, wahrgenommen wurde ${ }^{42}$. Fast alle in dieser Stadt residierenden Bücherkommissare standen nicht nur in kaijerlichen Diensten. Sie waren zugleich auch „von Ihro Päpstlichen Heiligkeit im heiligen Römischen Reich verordnete Bücher-Commissarii", also apostolische Bücherkommissare, und bezogen als solche auch ein Gehalt aus Rom. Diese Personalunion wal dem Wiener Hof und später auch dem Mainzer Kurfürsten und Erzkanzler des Reiches unbekannt. Erster päpstlicher Bücherkommissar war Valentin Leucht um $1600^{43}$.

Die Bücherkommission in Frankfurt ist nicht die einzige kaiserliche Kommission, die auf dem Gebiete des Bücher- und Pressewesens im Reich tätig geworden ist. Im Gegensatz zur Frankfurter Kommission, die 1597 zu einer ständigen Einrichtung geworden war und damit während der folgenden zwei Jahrhunderte einen festen Platz in dem System der Überwachung einnahm, handelte es sich bei den übrigen kaiserlichen Kommissionen um solche, die von Fall zu Fall zur Behandlung einzelner Vorkommn isse lediglich für eine begrenzte Zeit ins Leben gerufen wurden. Von der Kommission, die 1567 im Auftrage des Kaisers an der Universität Heidelberg Untersuchungen durchführte, wäre beispeilsweise zu berichten. Sie hatte eine Schrift mit dem Titel „Nachtigall" zu verfolgen, die als "Famoslibell” angesehen und folglich verboten wurde. In diesem Fall wurde an der Universität Heidelberg eine Untersuchung durchgeführt, weil die bezeichnete Schrift auch hier verbreitet worden war und zwei ortsansässige Buchdrucker in den Verdacht geraten waren, die Schrift gedruckt zu haben. Die eingeleitete Untersuchung und das nachfolgende Strafverfahren wurden unter der Aufsicht eines eigens dazu bestellten kaiserlichen Kommissars durchgeführt. Dieser Kommissar hatte allerdings nicht das Recht, das Verfahren selbst zu führen, denn dies war Sache der landesherrlichen Gerichte und Behörden. Der Kommissar wachte im Auftrag des Kaisers lediglich darüber, daß und wie die landesherrlichen Organe handel- 
ten. Auch in anderen Fällen, die den maßgeblichen Stellen in Wien besonders wichtig erschienen, wurden Spezialkommissionen eingesetz $t^{44}$.

Was die kaiserliche Oberaufsicht über das Bücher- und Pressewesen anbetrifft, so liefen beim Reichshofrat die Fäden aus dem ganzen Reich zusammen. Seiner unmittelbaren Aufsicht und Weisung unterstand die Bücherkommission in Frankfurt. Außer den laufenden Berichten ließ sich der Reichshofrat stets die Listen mit den Neuerscheinungen und, soweit es der Bücherkommission gelungen war, sie zu erhalten, die von den Druckern abgelieferten Pflichtexemplare zusenden, die er selbst begutachtete. Dort, wo die Frankfurter Kommission keinen Einfluß nehmen konnte, war der Reichshofrat auf die Informationen anderer kaiserlicher Organe sowie auf die Zusammenarbeit mit den landesherrlichen Behörden angewiesen. Der Reichshofrat konnte auf zweierlei Weise tätig werden, wenn er von der Verletzung der Reichsgesetze auf dem Gebiete des Bücher- und Pressewesens Kenntnis erhalten hatte: als Regierungsorgan des Reiches oder als Reichsgericht. Als Regierungsorgan versuchte er im Namen des Kaisers zu erreichen, daß die Landesherren die ihnen nach den Reichsgesetzen obliegenden Pflichten erfüllten, also Zensoren bestellten, welche die zum Druck gelangenden Bücher vorher durchsahen, oder Personen, die den Reichsgesetzen zuwider gehandelt hatten, durch ihre Gerichte aburteilen ließen. Das geschah in der Regel durch mehr oder minder scharf gehaltene, im Namen des Kaisers verfaßte, und deshalb mit seiner ganzen Autorität versehene Schreiben an die entsprechenden Landesherren, die einer solchen Aufforderung fast stets nachkamen, sich aber jedenfalls niemals offen zu widersetzen wagten, es sei denn, es handelte sich um eine Schrift, die der Landesherr und seine Behörden für nicht verbotswürdig erachteten. Letzeres kam in erster Linie bei Büchern mit religiösem Inhalt vor ${ }^{45}$.

Ebenso wie der Reichshofrat als Gericht über die genannten Straftatbestände urteilen konnte, war das Reichskammergericht dazu befugt. Dieselben Aufgaben, welche der Reichshoffiskal beim Reichshofrat hatte, oblagen dem Reichskammergerichtsfiskal für das Reichskammergericht ${ }^{46}$. Der Reichstag beschäftigte sich nicht nur generell mit dem Bücher- und Pressewesen, indem er bei der Reichsgesetzgebung auf diesem Gebiete mitwirkte. Er befaßte sich auch mit Einzelfällen. Erster Anlaß dazu waren 1521 die Schriften Luthers ${ }^{47}$. Als Landesherr hatte der Erzbischof und Kurfürst von Mainz das Recht und die Pflicht, mit Hilfe seiner Behörden in seinen Landen eine strenge Aufsicht über das Bücher- und Pressewesen auszuüben, eine Aufgabe, der sich die Mainzer Kurfürsten von jeher mit großer Sorgfalt gewidmet hatten. Die Tätigkeit des Kurfürsten von Mainz auf dem Gebiete des Bücher- und Pressewesens war jedoch nicht auf sein Territorium beschränkt. Als Erzkanzler des Reiches nahm er im Hinblick auf die Oberaufsicht über das Bücher- und Pressewesen im Reich ebenfalls Rechte für sich in Anspruch. Tatsächlich war sein Einfluß in dieser Hinsicht nicht gering ${ }^{48}$.

\section{Eingriffe in die kaiserlichen Rechte von der Seite der Kirche und iar Landesherrn}

Solange es ein kaiserliches Bücherregal gab, hat man von verschiedenen Seiten versucht, die Rechte des Kaisers auf dem Gebiete des Bücher- und Pressewesens zu beschränken. Gemeint sind nicht die Verstöße der Autoren, Drucker, Verleger und Händler gegen die bestehenden Reichsgesetze, sondern diejenigen planmäßigen Eingriffe verschiedener Reichsstände und der katholischen Kirche in die Rechte des Kaisers, die dem Ziele dienten, den eigenen Einfluß auf Buchdruck und Buchhandel zu vergrößern und ihn zum tragenden Faktor zu machen. Schon im 15. Jahrhundert ver- 
suchte die katholische Kirche, wie oben schon erörtert wurde, eine Kontrolle über Buchdruck und Buchhandel im deutschen Reich auszuüben. Papst Sixtus IV, erteilte der Universität Köln auf deren Anregung mit einem Breve vom 18. ${ }^{49}$ März 1479 den Auftrag, mit geeigneten Mitteln gegen Drucker, Käufer und Leser häretischer Schriften vorzugehen.

Einen Schritt weiter ging die Bulle, welche Papst Alexander VI. am 1. Juni 1501 erließ. Sie wandte sich in erster Linie an die Erzbischöfe von Köln, Mainz, Trier und Magdeburg, doch darf angenommen werden, daß eine Befolgung über das Gebiet dieser Erzbistümer hinaus erwartet wurde. Die Bulle weist darauf hin, daß seit der Erfindung der Buchdruckerkunst viele Bücher und Abhandlungen verbreitet worden seien, die Irrtümer und der christlichen Religion feindliche Lehren enthielten. Den am Buchdruck und Buchhandel Beteiligten wird bei Androhung der Strafe der Exkommunikation und einer durch die Erzbischöfe zu verhängenden Geldstrafe auferlegt, nichts zu drucken oder drucken zu lassen, was nicht zuvor von den Erzbischöfen oder ihren dazu bestellten Vertretern ausdrücklich erlaubt worden sei. Letztgenannten wird zur Pflicht gemacht, eine entsprechende Erlaubnis zu erteilen, wenn die Schriften nach dem Urteil von Sachverständigen und Strenggläubigen nichts enthielten, „was dem strengen Glauben zuwider, gottlos und Ärgernis erregend sei”. Außerdem ordnete die Bulle die Konfiszierung und Verbrennung derjenigen Bücher an, die etwas gegen die katholische Religion enthielten.

Leo X. wandte sich mit seiner Bulle vom 4. Mai 1515, mit der erneut die Vorzensur angeordnet wurde, an einen größeren Kreis. Sie war die Grundlage für das Mandat, das Kurfürst Albrecht von Mainz am 17. Mai 1517 für seine Lande erließ. Darin wurde im wesentlichen den in der Bulle von 1515 gestellten Forderungen Rechnung getragen, indem insbesondere noch einmal die Vorzensur und die Bücherinquisition verankert wurden. Damit war im deutschen Reich zum ersten Male ein wesentlicher Teil der päpstlichen Vorstellungen auf dem Gebiete des Bücher- und Pressewesens in weltlichen Rechtsnormen gefaßt und allgemein verbindlich geworden.

Das Konzil von Trient brachte im Vergleich mit den bisher von der Kirchenführung erlassenen Bestimmungen eine wesentliche Verschärfung der Vorschriften über Buchdruck und Buchhandel. Die Beschlüsse des Konzils hatten auf die Handhabung der Zensurbestimmungen im deutschen Reich großen Einfluß. Sinn der gefaßten Beschlüsse war es, den katholischen Glauben in der Weise zu schützen, daß das Drucken und Verbreiten aller Schriften verboten wurde, die geeignet waren, die katholische Religion oder die Person und die Autorität des Papstes anzugreifen oder in Zweifel zu ziehen. Mit dem Breve „Dominici gregis custodiae” vom 24. März 1564 ließ Papst Pius IV. den ersten Index verbotener Bücher veröffentlichen, der die Beschlüsse des Tridentinums berücksichtigte. In den folgenden Jahren wurde dieser „Index librorum prohibitorum, cum Regulis confectis per patres a Tridentina Synodo delectos, auctoritate Sanctiss. D. N. Pii IIII Pont. Max. comprobatus" in fast allen Ländern Europas veröffentlicht ${ }^{50}$

Die Beschlüsse des Tridentinums beeinflußten das Bücher- und Pressewesen in Deutschland nicht nur indirekt. Des öfteren wurden sie, obwohl kein Reichsrecht, unmittelbar zur Grundlage von Entscheidungen kaiserlicher Organe gemacht. Dafür sorgten schon diejenigen Mitglieder der kaiserlichen Bücherkommissionen, die zugleich apostolische Bücherkommissare waren, und sich die Durchsetzung der Konzils- 
beschlüsse zum Ziel gesetzt hatten. Der Versuch der katholischen Kirche, über das Amt des apostolischen Bücherkommissars die Beschlüsse des Tridentinums in den weltlichen Rechtsbereich zu übertragen, war ein Eingriff in das kaiserliche Recht der Bücheraufsicht, denn nach der Reichsverfassung hatte der Kaiser für die Wahrung des Religionsfriedens unter Beachtung der Parität im Hinblick auf die zugelassenen Konfessionen zu achten. Dabei war die gleiche Behandlung der Religionsparteien auf dem Gebiete des Bücher- und Pressewesens eine wesentliche Voraussetzung.

Die katholische Kirche versuchte nicht nur mit Anordnungen an die Erzbischöfe, die gleichzeitig Landesherren waren, sowie über die Bücherkommission in Frankfurt Einfluß auf das Bücher- und Pressewesen im Reich zu gewinnen. In vielen Fällen pflegten die Nuntien entweder aus eigenem Antrieb oder auf Weisung aus Rom den Kaiser auf bestimmte, ihrer Meinung nach dem katholischen Glauben abträgliche Schriften aufmerksam zu machen. Insgesamt gesehen unternahm die katholische Kirche große Anstrengungen, um Einfluß auf das Bücher- und Pressewesen im Reich zu gewinnen. Der Erfolg, der ihr dabei beschieden war, darf nicht unterschätzt werden ${ }^{51}$.

Gefahr drohte der kaiserlichen Rechtsposition vor allem von seiten der Territorialherren, denen die allgemeine politische Entwicklung im deutschen Reich - die Erstarkung der Macht der Territorien gegenüber dem Reich - zugute kam. Ungleich schwerer als die Eingriffe der katholischen Kirche in die Rechte des Kaisers waren diejenigen vieler Landesherren. Sie reichten von der Erteilung von Druckprivilegien in Konkurrenz mit den kaiserlichen bis zur Abschaffung der Zensur. Besonders die Erteilung von Druckprivilegien durch die Landesherrn nahm dem Kaiser viel von seinem überragenden Einfluß, den er ehemals auf Buchdruck und Buchhandel hatte ausüben können. Eisenhardt gibt als Beispiel die Haltung der sächsischen Kurfürsten; sie verstanden es stets, den Buchhandel im Lande und die Leipziger Messe in besonderer Weise zu fördern 52 .

Eisenhardt beurteilt auch die Motive, die zu einer scharfen Aufsicht über das Schrifttum führten, nicht ganz negativ. Eine Bewertung dieser Motive kann, so Eisenhardt, in der Zusammenfassung seines Buches, nicht nach heutigen Maßstäben erfolgen, und er behauptet: „Trotz der durch religiösen Eifer verursachten Erscheinungen sollte man den Hauptzweck einer strengen Beaufsichtigung des Bücher- und Pressewesens über zwei Jahrhunderte hinweg nicht aus den Augen verlieren: eine scharfe Kontrolle des Schrifttums sollte mit dazu beitragen, den 1555 mühsam errungenen Religionsfrieden zu bewahren - ein Ziel, welches im Prinzip auch heute nicht anders als positiv bewertet werden kann. Auch der 30jährige Krieg und seine verheerenden Folgen dürfen nicht darüber hinwegtäuschen, daß die Aufsicht über das Bücher- und Pressewesen ganz wesentlich dazu beigetragen hat, noch mehr durch religiöse Auseinandersetzungen verursachte Konflikte vermeiden zu helfen. So hat die Aufsicht über das Bücher- und Pressewesen eine der Voraussetzungen dafür geschaffen, daß die Angehörigen zweier ursprünglich untereinander völlig verfeindeter großer Konfessionen schließlich in einem staatlichen Gebilde miteinander leben konnten." 53

Bis zur Mitte des 18. Jahrhunderts gab es außerdem kaum ein Bewußtsein für die Existenz von Freiheitsrechten. Gabriel Putherbeien von Thuron zum Beispiel veröffentlichte im 16. Jahrhundert einen Rechtfertigungsversuch des Zensursystems ${ }^{54}$. Putherbeien lebte in der Zeit, da insbesonders mit Karl V. die Zensurgewalt unter Leitung und Aufsicht der Kirche in weltliche Hände überzugehen begann. Er forderte 
die weltliche Obrigkeit auf, „gute, starcke, würckliche Mandat ausgehn” zu lassen, „mit aufgelegter penlicher straff, dass fortan niemands mehr solche oder dergleichen Bücher dichtet, schrieb, trucket, oder fail hatte". Putherbeien schrieb - nach dem augenblicklichen Stand der Forschung - die älteste deutschsp rachige theoretische Abhandlung über den Journalismus unter dem Titel: „Von Verbot unnd auffhebung deren Bücher und Schrifften, so in gemain ohne nachtheil unnd verletzung des gewissens, auch der frumb und erbarkeit, nit mögen gelesen oder behalten werden", das in deutscher Sprache 1581 in München erschien. Abhilfe für Schäden in kommunikativen Bereich sucht der Autor bei der Macht weltlicher und geistlicher Obrigkeit. Er macht keine konkreten Vorschläge für Zensurierungen und Reglementierungen, zeigt nur die Grundlinien dèr materiellen Beschränkung, nicht aber Details eines formellen Verbots.

\section{Fazit}

Abschließend kann man fragen, welche praktische Wirkung die kaiserliche und kirchliche Oberaufsicht über das Bücher- und Pressewesen gehabt hat. Man kann, was die kaiserliche Oberaufsicht im Reich betrifft, die Antwort von Eisenhardt wiederholen: die praktische Wirkung war stets nach Ort und Zeit verschieden und läßt sich für alle besprochenen Zeiträume schwer abschätzen, aber „Daß die Reichsgesetzgebung und ihre Handhabung in den Territorien im 16. und 17. Jahrhundert den Autoren, Buchdruckern und Buchhändlern schwer zu lösende Fesseln angelegt hat steht außer Zweifel"55. In seiner Besprechung des Buches von Eisenhardt hat Heinz-Dietrich Fischer eigentlich eine klare Antwort auf dieses Problem formuliert, als er schrieb: „Es müßte aufgrund von Spezialuntersuchungen über verschiedene Bereiche des Reiches festgestellt werden, inwieweit diese These (von Eisenhardt über die praktische Wirkung der kaiserlichen Oberaufsicht), welche doch vor Überschätzung der Wirkungsmöglichkeiten der zentralen Kommunikationsnormen warnt, durchgängig bestätigt werden kann." 56

\section{Anmerkungen}

* Bei diesem Beitrag handelt es sich zum Teil um den Vorabdruck eines Kapitels (Pressezensur im Reformationszeitalter, 1475-1648) aus dem demnächst im Verlag Dokumentation Saur KG (München) in der von Prof. Dr. Heinz-Dietrich Fischer herausgegebenen Reihe 'Publizistischhistorische Beiträge' erscheinenden Sammelband 'Deutsche Kommunikationskontrolle des 15. bis 20. Jahrhunderts'. Den Herausgeber dieses Werkes, Prof. Dr. Fischer (Ruhr-Universität Bochum) dankt CS für die Genehmigung zum Vorabdruck.

1 Vgl. im folgenden Franz Schneider: Die Freiheit der Meinungsäußerung in der griechischen Demokratie und römischen Republik, in: „Publizistik” (Bremen), 7. Jg./Heft I (JanuarFebruar 1962), S. 6 ff.

2 Rudolf Düll: Das Zwölftafelgesetz, München 1944, S. 49.

3 Ulrich Eisenhardt: Die kaiserliche Aufsicht über Buchdruck, Buchhandel und Presse im Heiligen Römischen Reich Deutscher Nation (1496-1806). Ein Beitrag zur Geschichte der Bücher- und Pressezensur, Karlsruhe 1970, S. 4. 
4 Erich Traumann: Zeitung und kirchliche Zensur. Ein Beitrag zur Pressekunde. Vergleichende und geschichtliche Darstellung, phil. Diss. Heidelberg, Hildesheim 1936, S. 4. - Traumann wollte keine Verteidigung und Rechtfertigung der kirchlichen Zensur schreiben; er versuchte, die Entwicklung der kirchlichen Zeitungszensur - die einen Ausschnitt aus dem Großgebiet der Büchergesetzgebung darstellt - in ihrea. Wandlungen darzulegen.

5 Martin Löfller: Presserecht, Bd. 1, 2. Aufl, München 1969, S. 31.

${ }^{6}$ P. Kloeppel: Das Reichspreßrecht, Leipzig 1894, S. 12.

7 Viktor Muckel: Die Entwicklung der Zensur in Köln, jur. Diss. Köln, Würzburg 1932, S. 7 f.

${ }^{8}$ Erich Traumann, a.a.O., S. 3.

9 Viktor Muckel; a.a.O., S. 5.

10 Erich Traumann, a.a.O., S. 22; vgl. Anmerkung 15.

11 Ulrich Eisenhardt (a.a.O., S. 5) schreibt: 18. März, Traumann (a.a.O., S. 32) dagegen: 17. März.

2 Viktor Muckel, a.a.O., S. 9 und 11.

13 Ulrich Eisenhardt, a.a.O., S. 4; er beruft sich dabei auf Albrecht Kirchhoff: Beiträge zur Geschichte des deutschen Buchhandels, Leipzig 1851, S. 43.

14 Ulrich Eisenhardt, a.a.O., S. 4.

15 Viktor Muckel (a.a.O., S. 19) schreibt: 1478, was wahrscheinlich einen Druckfehler darstellt; Erich Traumann (a.a.O., S. 22) schreibt: 12. November.

16 Viktor Muckel, a.a.O., S. 19 f.

17 Daselbst, S. $13 \mathrm{ff}$.

18 Daselbst, S. 23.

14 Erich Traumann, a.a.O., S. $31 \mathrm{ff}$.

20 Viktor Muckel, a.a.O., S. 1 ff.

21 Vgl. für die Texte Erich Traumann, a.a.O., S. 39 f.

22 Ulrich Eisenhardt (a.a.O., S. 133) nennt 1564, Erich Traumann (a.a.O., S. 40) dagegen 1565.

23 Text nach Erich Traumann, a.a.O., S. 39 f.

24 Daselbst, S. $42 \mathrm{f}$.

25 Vgl. Viktor Muckel (a.a.O., S. 34) für die Situation in Köln in der ersten Hälfte des 16. Jahrhunderts.

26 Text nach Erich Traumann, a.a.O., S. 44 f.

27 Daselbst, S. 48. Siehe für die Versuche der katholischen Kirche, Einfluß auf die Kontrolle der Druckschrilten zu gewinnen, auch Ulrich Eisenhardt, a.a.O., S. $132 \mathrm{ff}$.

28 Ulrich Eisenhardt, a.a.O., S. 5.

${ }^{24}$ Daselbst, S. 24 f.; vgl. auch Kurt Koszyk: Vorläufer der Massenpresse. Ökonomie und Publizistik zwischen Reformation und Französischer Revolution. Öffentliche Kommunikation im Zeitalter des Feudalismus, München 1972, S. 22 f. und Heinz-Dietrich Fischer: Erscheinungsformen der Kontroverspublizistik religiöser 'Parteien' in Reformationszeitalter, in: „Communicatio Socialis" (Paderborn), 7. Jg./Heft 2 (April-Juni 1974), S. 119-127.

${ }^{30}$ Ulrich Eisenhardt, a.a.O., S. $6 \mathrm{f}$.

31 Daselbst, S. $27 \mathrm{ff}$.

32 Daselbst, S. 7 ff.

33 Daselbst, S. 10.

34 Daselbst, S. 46 if 
35 Daselbst S. 48; vgl. außerdem Margot Lindemann: Deutsche Presse bis 1815, Berlin 1969, S. $53 \mathrm{ff}$.

36 Ulrich Eisenhardt, a.a.O., S. 49.

37 Daselbst, S. $54 \mathrm{ff}$.

38 Daselbst, S. 153.

39 Daselbst, S. 2.

40 Daselbst, S. 63.

4 Daselbst, S. 64 f.

42 Daselbst, S. 68 f.

43 Daselbst, S. 82.

44 Daselbst, S. 64 und S. 92.

45 Daselbst, S. 93

46 Daselbst, S. 95.

47 Daselbst, S. 96.

48 Daselbst, S. 97; vgl. detailliert Hilger Freund: Die Bücher- und Pressezensur im Kurfürstentum Mainz von 1486-1797, Karlsruhe 1971.

$49 \mathrm{Vgl}$. Anmerkung 11. Die Veröffentlichung: Die Bücherverbote in Papstbriefen. Kanonistischbibliographische Studie von Joseph Hilgers S.J., Freiburg im Breisgau 1907, verzeichnet alle oben genannten und nicht genannten in apostolischen Schreiben ergangenen Bücherverbote. Sie enthält somit den Index der auf diese nachdrücklichste Weise unmittelbar durch die Päpste selbst verbotenen Schriften. Alle päpstlichen Urkunden, durch welche im Laufe der Jahrhunderte jene Schriften verurteilt wurden, werden in den beiden ersten Teilen der Arbeit mit ihrem Titel, Datum und Fundort aufgeführt. Diejenigen Papstbriefe, welche sich in keiner der bekannten Sammlungen finden, sind im dritten Teile als Anlagen vollständig wiedergegeben.

so Vgl. Albert Flocon: L'Univers des livres. Etude hitorique des origines à la fin du XVIle siècle, Paris 196l, S. 403-404.

51 Ulrich Eisenhardt, a.a.O., S. 132 ff.

52 Daselbst, S. $135 \mathrm{f}$.

53 Daselbst, $\mathrm{S}$. $153 \mathrm{f}$.

54 Franz Schneider: Die Schrift Gabriel Putherbeiens von Thuron aus dem Jahre 1549/1581 in ihrer publizistik-wissenschaftlichen Bedeutung, in: „Publizistik” (Konstanz), 8. Jg./Heft 4 (Juli-August 1963), S. 354 ff.

55 Ulrich Eisenhardt, a.a.O., S. 154.

56 In: „Publizistik” (Konstanz), 16. Jg./Heft 3 (Juli-September 1971), S. 322 f., hier S. 323. 


\section{SUMMARY}

The practice of censorship still existing in some countries raises the question of the origins of such an institution. The answer that the Church must have been the instigator is as simplistic as it is contestable. In 1479 Pope Sixtus IV asked the University of Cologne, upon its own recommendation, to proceed with appropriate means of counteracting printers, buyers and readers of heretical literature. As early as 1517 an essential part of the Church's attitude towards books and periodicals was inserted into the civil laws for the first time in the German Empire, and declared generally binding. Although the conclusions of the Council of Trent did not become the law of the Empire, they formed the basis of many decisions made by Imperial bodies. In 1564 Pope Pius IV published the first Index of Prohibited Books in the light of the Tridentine conclusions. Feelings of insecurity and anxiety were reasons for the establishment of censorship, and its practice during Reformation times (1478-1648) can be considered as one of the first important reactions to a changing Christian outlook. Church and State worked together to withstand the challenge to the endangered structure of the medieval "Weltbild". The effects of this surveillance by both religious and civil authorities on books and periodicals produced during the Reformation are uneven, and further studies are necessary. One result, however, was that until the mid-18th century there was no awareness of the general nights of human freedom.

\section{RÉSUMÉ}

La censure, encore en pratique dans de très nombreux pays, suscite la question de l'origine de la censure. La réponse disant que l'Eglise est l'inventeur du contrôle de la communication, est aussi simple que contestable. En l'an 1479, le Pape Sixte IV de l'université de Cologne donna l'ordre, sous l'impulsion de cette dernière, d'agir avec les moyens appropriés contre les im. primeurs, les vendeurs et les lecteurs d'oeuvres hèrétiques. Dejà en 1517, pour la première fois dans l'Empire allemand, on reunit une partie importante des représentations écclesiastiques dans le domaine des livres et de la presse en normes juridiques laïques et on les declara en règle générale obligatoires. Les décisions du Concile de Trente, quoique n'étant pas de droit impérial, furent immédiatement considérées comme base de jugement des organes impérieux. Le Pape Pie IX fit publier en 1564 le premier index des livres interdits qui prenait en considération les décisions du Concile de Trente. Le manque d'assurance et la peur sont les motifs qui ont conduit à l'établissement de la censure. Ainsi on peut considérer la censure à l'époque de la Réformation (1479-1648) comme le premier réflexe légal important du grand bouleversement de l'humanite chretienne. L'Eglise et l'Etat travaillèrent ensemble contre la mise en danger de la structure de la vision du monde médiévale. L'influence de la surintendance écclesiastique et impériale sur les livres et la presse à l'époque de la Réformation était constamment différente selon l'heure et le lieu, elle ne se laisse évaluer plus exactement qu'à l'aide de recherches plus approfondies. En outre, on avait, jusqu'au milieu du $18 \mathrm{e}$ siècle, à peine conscience de l'existence des droits à la liberté.

\section{RESUMEN}

La practica de la censura, todavia vigente en tantos paises, plantea el interrogante sobre su origen. La version, según la cual la Iglesia es la inventora de este control en la comunicacion social, es tan simple como discutible. En el año 1479 el papa Sixto IV dió a la Universidad de Colonia, que lo habia solicitado, atribuciones para actuar con medios adecuados contra los impresores, compradores y lectores de escritos heréticos. Ya en 1517 el Imperio Germánico trasladó, por primera vez, una parte esencial de los criterios eclesiásticos a normas juridicas civiles para la censura de libros y otras publicaciones. Los cánones del Concilio de Trento, aunque no eran 
derecho para el Imperio, se convirtieron inmediatamente en base para las decisiones de organismos imperiales. El papa Pio IV publicó en 1564 el primer Indice de libros prohibidos, a tenor de los cánones del Tridentino. La implantación de la censura responde a sentimientos de inseguridad y miedo. Así, en tiempos de la Reforma (1479-1648) puede considerarse la censura como primera reacción legal importante a la mayor revolución de la humanidad cristiana. Iglesia y Estado colaboran contra los peligros que amenazan la estructura de la cosmovisión medieval. El control eclesiástico e imperial sobre las publicaciones durante la época de la Reforma fué distinta en los diversos lugares y momentos y solo puede valorarse con análisis más extensos. Por otra parte, apenas existe hasta mediados del siglo XVIII consciencia de la existencia de los derechos de la libertad. 